\title{
The A allele of cluster of differentiation 36 (CD36) SNP 1761667 associates with decreased lipid taste perception in obese Tunisian women
}

\author{
Ines Mrizak ${ }^{1}$, Omar Šerý ${ }^{2,3}$, Jiř́ Plesnik ${ }^{3,4}$, Amel Arfa ${ }^{1}$, Mariem Fekih ${ }^{1,5}$, Ali Bouslema ${ }^{1}$, Monia Zaouali ${ }^{1}$, \\ Zouhair Tabka ${ }^{1}$ and Naim Akhtar Khan ${ }^{4 *}$ \\ ${ }^{1}$ Department of Physiology and Functional Exploration, Farhat Hached University Hospital, Sousse, Tunisia \\ ${ }^{2}$ Institute of Animal Physiology and Genetics, Academy of Science, Veveři 97, 60200 Brno, Czech Republic \\ ${ }^{3}$ Laboratory of Neurobiology and Molecular Psychiatry, Laboratory of Molecular Physiology, Department of Biochemistry, \\ Faculty of Science, Masaryk University, Kotlářská 2, 61137 Brno, Czech Republic \\ ${ }^{4}$ Physiologie de la Nutrition et Toxicologie, UMR U866 INSERM/Université de Bourgogne/Agro-Sup, 6, Boulevard Gabriel, \\ Dijon 21000, France \\ ${ }^{5}$ Department of Biochemistry, Sabloul University Hospital, Sousse, Tunisia
}

(Submitted 1 July 2014 - Final revision received 6 December 2014 - Accepted 16 January 2015 - First published online 30 March 2015)

\section{Abstract}

Recent studies have suggested that excessive intake of dietary fat is associated with obesity. Some obese subjects have been reported to exhibit high thresholds for the gustatory detection of lipids via lipid receptors, such as cluster of differentiation 36 (CD36). We studied lingual detection thresholds for emulsions containing oleic acid in obese Tunisian women ( $n$ 203) using a three-alternative forced choice (3-AFC) method. Genotyping of the TNF- $\alpha$ (rs1800629), IL-6 (rs1800795) and CD36 (rs1761667) genes was performed to associate with lipid taste perception thresholds. The $C D 36$ genotype distribution was as follows: GG ( $n$ 42), AG ( $n$ 102) and AA ( $n$ 59). Women with the CD36 GG genotype exhibited oral detection thresholds for oleic acid that were more than three times lower than those with the CD36 AA genotype. The present study confirms a high threshold of gustatory fat detection in obese women with the CD36 AA genotype, but there is no significant association with the $I L-6$ and $T N F-\alpha$ gene polymorphisms.

Key words: Obesity: Lipids: Taste: Genes

As the obesity epidemic continues, more subjects are getting fatter and are therefore at increased risk for metabolic complications, hypertension and cancer-related mortality ${ }^{(1,2)}$. The aetiology of obesity is multifactorial, and genetic inheritance and behavioural/environmental causes are considered to be the main factors ${ }^{(3)}$. Dietary fat is considered palatable to humans, and several factors, including its olfactory, visual and textural properties, have been proposed as playing a key role in the attractiveness of $\mathrm{fat}^{(4)}$. Humans and rodents can detect long-chain fatty acids in their diets as gustatory cues $^{(4-9)}$. Some recent studies have shown that obese subjects exhibit a high preference for dietary lipids as compared to lean subjects ${ }^{(10,11)}$, which suggests that inappropriate lipid perception might influence obesity risk by impacting feeding behaviour. In fact, obesity is associated with a low sensitivity to the oro-sensorial detection of fat ${ }^{(10,11)}$.

Lingual cluster of differentiation 36 (CD36), like G proteincoupled receptor 120 (GPR120) and G protein-coupled receptor 40 (GPR40), has been shown to act as a lipid receptor that is involved in a spontaneous preference for fat ${ }^{(6,12-15)}$. The lingual lipid receptors bind to long-chain fatty acids, which are released by lingual lipases in the buccal cavity $^{(12-15)}$. We performed the present study on CD36 SNP because CD36 is a high-affinity receptor, whereas GPR120 and GPR40 are low-affinity receptors. In addition, GPR40 could not be detected on human lingual epithelium ${ }^{(16)}$. Moreover, Sclafani et $a l .{ }^{(17)}$ have shown that CD36 is directly involved in early fat detection, whereas GPR120 plays a role in the post-ingestive regulation of fat preference ${ }^{(18)}$.

Recent studies have shown that CD36 protein expression is influenced by $C D 36$ gene polymorphism, and it is related to the detection threshold of dietary lipids in obese subjects ${ }^{(19)}$. Keller et $a l{ }^{(20)}$ reported that obese subjects with the CD36 AA genotype (rs1761667) perceived more creaminess in salad as compared to those with the AG or GG genotypes. Pepino et al. ${ }^{(19)}$ reported that obese subjects with the AA genotype exhibited higher oral detection thresholds for fat than those with the AG and GG genotypes. These novel findings

Abbreviations: GPR120, G protein-coupled receptor 120; HbA1c, glycosylated Hb.

*Corresponding author: Professor N. A. Khan, fax +33 3803963 30, email naim.khan@u-bourgogne.fr 
are changing our view about the pathogenesis of obesity; however, future studies must be conducted to confirm these interesting findings, particularly in developing countries where obesity is quickly rising.

In chronic pathological conditions such as obesity, IL-6 plays a synergic role in inflammation ${ }^{(21-23)}$, because macrophages within adipose tissue might secrete IL-6 ${ }^{(22)}$. An association between the rs1800795 polymorphism of the $I L-6$ gene and increased adiposity, inflammation and metabolic disturbances has been demonstrated ${ }^{(24,25)}$. In obesity, adipose tissues also secrete TNF- $\alpha$ abundantly ${ }^{(26)}$, and rs1800629 polymorphism of the $T N F-\alpha$ gene ${ }^{(27)}$ has been reported to be associated with obesity risk ${ }^{(28)}$ as well as a high incidence of type 2 diabetes ${ }^{(29)}$. Because obesity is marked by inflammation, the present study is also designed to explore the relationship between pro-inflammatory markers (IL-6, TNF- $\alpha$ and C-reactive protein) and the oro-sensorial detection of lipids in obese subjects.

There has recently been a rapid upsurge in overweight/ obesity and obesity-related diseases in Tunisia, especially in women as compared to men ${ }^{(30,31)}$. This sex gap between women and man differs greatly according to environmental and socio-economic conditions ${ }^{(31)}$. Keeping in mind the aforementioned literature on lipid oral taste sensitivity and CD36 SNP, we thought it would be worthwhile to investigate whether CD36 SNP in obese Tunisian women is associated with decreased fat taste perception.

\section{Materials and methods}

\section{Subjects}

Inclusion criteria. Obese women ( $n$ 203) were recruited from the group of patients who visited the gynaecology outpatient department (OPD) of Farhat Hached University Hospital, Sousse (Tunisia), in 2012 and 2013 for a general health check-up. Medical records were screened by specialist clinicians. The studied women were between 38 and 43 years old. The women were asked to return to the gynaecology OPD when they were in their first week of menstruation, and they were given an appointment for a particular date so that blood sampling and an analysis of other parameters could be performed.

The exclusion criteria included smoking, diabetes, breastfeeding, pregnancy-related complications, a history of gestational diabetes, the use of oral contraception, chronic illness such as hypertension or any other inflammatory pathology, any autoimmune disease, any lipid-lowering medication, recent weight loss, dieting and the use of any medications known to affect taste. The inclusion criterion constituted a normal glucose tolerance test and electrocardiograms.

Anthropometrics. Body weight and height were measured in the morning while participants were unclothed and not wearing shoes. BMI was calculated as body weight (in $\mathrm{kg}$ ) divided by height (in $\mathrm{m}^{2}$ ). Obesity was defined as a BMI of $30 \mathrm{~kg} / \mathrm{m}^{2}$ or higher, in accordance with the recommendations of WHO. The characteristics of the women are shown in Table 1.
Table 1. Clinical characteristics of obese Tunisian women ( $n$ 203) (Mean values and standard deviations)

\begin{tabular}{|c|c|c|}
\hline Parameters & Mean & SD \\
\hline Weight (kg) & $86 \cdot 4$ & $16 \cdot 3$ \\
\hline Height $(\mathrm{cm})$ & 158 & 6 \\
\hline BMI $\left(\mathrm{kg} / \mathrm{m}^{2}\right)$ & 34.6 & $4 \cdot 2$ \\
\hline TNF- $\alpha(\mathrm{pg} / \mathrm{ml})$ & 131.4 & 165.5 \\
\hline IL-6 (pg/ml) & $73 \cdot 3$ & $48 \cdot 7$ \\
\hline Age (years) & 38.4 & 11.4 \\
\hline Glucose (mmol/l) & 5.97 & 1.84 \\
\hline Urea (mmol/l) & 3.39 & 1.58 \\
\hline Creatinine $(\mu \mathrm{mol} / \mathrm{l})$ & 60.39 & 14.58 \\
\hline Cholesterol ( $\mathrm{mmol} / \mathrm{l})$ & 5.08 & 1.29 \\
\hline TAG (mmol/l) & $1 \cdot 77$ & 1.06 \\
\hline $\mathrm{HDL}(\mathrm{mmol} / \mathrm{l})$ & $1 \cdot 14$ & 0.31 \\
\hline $\mathrm{LDL}(\mathrm{mmol} / \mathrm{l})$ & 3.04 & 1.01 \\
\hline HbA1c (\%) & $5 \cdot 60$ & 1.22 \\
\hline ApoA1 (g/l) & $2 \cdot 04$ & 0.74 \\
\hline ApoB $(g / l)$ & $1 \cdot 26$ & $1 \cdot 13$ \\
\hline Insulin (pmol//) & 78.76 & 67.64 \\
\hline CRP (mg/l) & $7 \cdot 8$ & $7 \cdot 8$ \\
\hline
\end{tabular}

HbA1c, glycosylated $\mathrm{Hb}$; CRP, C-reactive protein.

\section{Ethics}

The present study was carried out in accordance with the Declaration of Helsinki (1989) of the World Medical Association and was approved by Farhat Hached Hospital Committee for Research on Human Subjects (Tunisia). Informed written consent was obtained from all of the subjects. The present experimental protocol conforms to the relevant ethical guidelines for human research.

\section{Blood samples}

Fasting venous blood samples were collected from each woman to obtain plasma (EDTA tubes) and serum. Serum and plasma were prepared by centrifugation $(1000 \boldsymbol{g}$ at 20 min). Plasma was immediately used for glucose determination. Serum was aliquoted and frozen at $-80^{\circ} \mathrm{C}$ for further analysis of blood parameters.

\section{Determination of blood parameters}

Serum TAG, total cholesterol and free cholesterol concentrations were determined using enzymatic methods, according to the manufacturer's instructions furnished with the kit (Boehringer). HDL-cholesterol was also measured by a kit (Boo Scientific). LDL-cholesterol concentrations were calculated according to Friedewald et al. ${ }^{(32)}$. All biochemical parameters were analysed on a Synchron CX7 Clinical System (Beckman). Plasma fasting glucose was determined by the glucose oxidase method with a glucose analyser (Beckman Instruments). Plasma glycosylated $\mathrm{Hb}$ (HbA1c) concentrations were determined by isolab column chromatography ${ }^{(33)}$. Insulin serum concentrations were determined using an Insulin IRMA kit (Immunotech; Beckman Coulter, Inc.) with a detection limit of $0.5 \mu \mathrm{IU} / \mathrm{ml}(3.4725 \mathrm{pmol} / \mathrm{l})$. The inter-assay CV was 3.3 and $4 \%$ for the 13 and $54 \mathrm{IU} / \mathrm{ml}$ (90.285 and $375.03 \mathrm{pmol} / \mathrm{l})$ concentrations, respectively. 
Serum concentrations of urea, creatinine and C-reactive protein were analysed by routine standard techniques using an automated Synchron CX7 Clinical System (Beckman). Serum concentrations of IL-6 and TNF- $\alpha$ were measured with ELISA kits (Immunotech).

\section{Oleic acid sensitivity analysis}

Taste emulsions containing food grade oleic acid (Sigma) were prepared according to Chalé-Rush et $a l .{ }^{(34)}$. EDTA $(0.01 \%, \mathrm{w} / \mathrm{v})$ was added to prevent fatty acid oxidation. The emulsions were sonicated for $4-5 \mathrm{~min}$ in a Labo-Modern sonicator at $4^{\circ} \mathrm{C}$ in an ice bath. Samples were stored in opaque polypropylene tubes and used for testing within $48 \mathrm{~h}$ of preparation. Control samples were prepared in the same way but without added oil.

The women were called on a stipulated date and advised to arrive early in the morning without having eaten breakfast (fasting state). The subjects were weighed, and a blood sample was drawn before the preference test to assess blood parameters. Taste preference tests for dietary lipids were performed by employing oleic acid at different ascending concentrations $(0 \cdot 018,0 \cdot 18,0 \cdot 37,0 \cdot 75,1 \cdot 5,3,6$ and $12 \mathrm{mmol} / \mathrm{l})$ by using a three-alternative forced choice (3-AFC) method ${ }^{(35)}$. According to the 3-AFC method, the patients were instructed to taste, one by one, three solutions; two of the solutions contained a control substance (acacia gum, 0.01\%), and the third one contained oleic acid in a solution that also included acacia gum (0.01\%). The acacia gum was used to mimic the textural properties of oil in the control solution.

We increased the concentration of oleic acid in the test solution when a single incorrect response was given, and we decreased the quantity of this fatty acid after two correct responses, in accordance with the method described by Pepino et $a l^{(19)}$. A reversal in the response was considered when the concentration sequence changed direction. The procedure was terminated when there were four reversals that met the following two criteria. First, there could not be more than two dilution steps between two successive reversals. Second, the series of reversals could not form an ascending pattern. The threshold concentration was calculated as mean of log values for the last four reversals. To avoid visual and olfactory cues, the testing session was conducted under red light and participants used nose clips. The women were not allowed to drink the solutions; rather, they had to spit out each solution after keeping it in their mouths for a few seconds. If they responded that they observed no difference in the taste sensation, we increased the concentration of oleic acid. If they were able to detect a difference, it meant they were capable of detecting the presence of 'fatty taste'.

\section{Genotyping analyses}

Genomic DNA was extracted from $5 \mathrm{ml}$ of whole blood with the use of a commercially available DNA isolation kit (Wizard Genomic DNA purification kit; Promega Corporation) according to the manufacturer's protocol. Genotyping of
TNF- $\alpha-308$ G/A (rs1800629), IL-6 - 174 G/C (rs1800795) and $C D 36 \mathrm{~A} / \mathrm{G}$ (rs1761667) was performed according to methods that have been previously used by our laboratory ${ }^{(36,37)}$. The PCR primers for the three genotypes were as follows: (TNF- $\alpha$ : 5'-AGG CAA TAG GTT TTG AGG GGC AT-3' and 5'-CGG GGA AAG AAT CAT TCA ACC AG-3'; CD36: 5'-CAA AAT CAC AAT CTA TTC AAG ACCA- $3^{\prime}$ and $5^{\prime}$-TTT TGG GAG AAA TTC TGA AGA G-3'; IL-6: $5^{\prime}$-ACT TTT CCC CCT AGT TGT GTC TTT C- $3^{\prime}$ and $5^{\prime}$-AGA ATG AGC CTC AGA CAT CTC CAG T-3'). PCR amplification reactions were performed in a Veriti thermal cycler (Life Technologies). After initial denaturation for $3 \mathrm{~min}$ at $95^{\circ} \mathrm{C}$, DNA was subjected to further amplification as follows for $T N F-\alpha$ and $I L-6$ : denaturation for $30 \mathrm{~s}$ at $95^{\circ} \mathrm{C}$, annealing for $30 \mathrm{~s}$ at $66^{\circ} \mathrm{C}$ and extension for $30 \mathrm{~s}$ at $72^{\circ} \mathrm{C}$. After thirty-five cycles, a final extension for $5 \mathrm{~min}$ at $72^{\circ} \mathrm{C}$ was used. Amplified DNA was digested by either endonuclease Ncol $(T N F-\alpha)$ or TaqI (IL-O) and further incubated at either $37^{\circ} \mathrm{C}$ for $16 \mathrm{~h}(T N F-\alpha)$ or $65^{\circ} \mathrm{C}$ for $5 \mathrm{~h}$ (IL-O). For $C D 36$, the conditions were as follows: denaturation for $30 \mathrm{~s}$ at $95^{\circ} \mathrm{C}$, annealing for $30 \mathrm{~s}$ at $56^{\circ} \mathrm{C}$ and extension $30 \mathrm{~s}$ at $72^{\circ} \mathrm{C}$. After forty cycles, a final extension for $5 \mathrm{~min}$ at $72^{\circ} \mathrm{C}$ was used. Amplified DNA was digested by Hha1 at $37^{\circ} \mathrm{C}$ for $30 \mathrm{~min}$. The digestion products were analysed by $2 \%(\mathrm{w} / \mathrm{v})$ agarose gel electrophoresis (Elisabeth Pharmacon) containing ethidium bromide, and DNA fragments were visualised under UV light. The following fragments were detected for $T N F-\alpha$ : 264 bp (GG genotype), 264 and 284 bp (AG genotype) and $284 \mathrm{bp}$ (AA genotype). For $I L-6$, two fragments of 24 and $180 \mathrm{bp}$ ( $\mathrm{G}$ allele) and an unrestricted fragment of $204 \mathrm{bp}$ (C allele) were obtained. Two fragments of CD36 (138 and $52 \mathrm{bp}$ ) in the presence of the $\mathrm{G}$ allele were visualised, and an unrestricted fragment (A allele) had a length of $190 \mathrm{bp}$.

\section{Statistical analysis}

CSS Statistica software (StatSoft) was used for statistical analysis. An ANOVA was used for correlation of the different parameters and genotypes. A Kruskal-Wallis test was used for one-way analyses on ranks. The $\chi^{2}$ test was used for the comparison of genotype frequencies. Fisher's exact test was used for the comparison of allelic frequencies. For correlation studies, we used Pearson's correlation coefficient method. Dunn's method was used for all pairwise multiple comparisons between the AA, AG and GG genotypes and the detection thresholds.

\section{Results}

\section{Subject characteristics}

Table 1 shows the anthropometric measures and concentrations of different blood parameters in the present cohort of obese Tunisian women ( $n$ 203). The values of glucose, insulin, urea, creatinine, cholesterol, HDL, LDL, HbA1c, apoA1, apoB, insulin and C-reactive protein were within normal ranges for obese women. Serum TAG, IL-6 and TNF- $\alpha$ concentrations were higher in the women as compared to previously reported control values ${ }^{(38,39)}$. 
Table 2. Genotype frequencies in obese Tunisian women

\begin{tabular}{lcccc}
\hline Gene & SNP ID & Genotype & All subjects & Frequencies \\
\hline CD36 & rs1761667 & GG/AG/AA & $42 / 102 / 59$ & $0 \cdot 21 / 0 \cdot 50 / 0 \cdot 29$ \\
TNF- $\alpha$ & rs1800629 & GG/GA/AA & $140 / 56 / 7$ & $0 \cdot 69 / 0 \cdot 27 / 0 \cdot 04$ \\
IL-6 & rs1800795 & GG/GC/CC & $146 / 47 / 10$ & $0 \cdot 72 / 0 \cdot 23 / 0 \cdot 05$ \\
\hline
\end{tabular}

$C D 36$, cluster of differentiation 36 .

\section{CD36 genotype and oleic acid detection thresholds}

Table 2 shows the genotype frequencies of three polymorphisms in the present cohort of obese women. Fig. 1 shows that the subjects with the GG genotype of the CD36 gene had thresholds for oleic acid detection that were 3.3 times lower than those of subjects with the AA genotype (95\% CI of relative risk $2.5032,4.4298$, OR $9.9615 ; 95 \%$ CI of OR 6.2101, 15.9793). We did not observe a statistically significant difference in the taste detection thresholds of subjects with the AG or the AA (or GG) genotypes. It is also noteworthy that some subjects, which have been termed non-tasters, could not detect fatty acid even at the highest concentration. There were a total of four non-tasters in the AA, AG and GG genotypes of CD36 gene (Fig. 1).

\section{Association between cholesterol, LDL and glycosylated $\mathrm{Hb}$ and CD36 polymorphism}

Fig. 2(a) and (b) shows that cholesterol and LDL concentrations were significantly lower in subjects with the CD36 GG and AG genotypes than in subjects with the AA genotype $(P<0 \cdot 01)$. Interestingly, the women with the GG genotype exhibited higher HbA1c plasmatic concentrations than did those with the AA genotype $(P<0.05)$ (Fig. 2(c)).

\section{CD36 genotypes and TNF- $\alpha$ and IL-6 concentrations}

Serum concentrations of TNF- $\alpha$ was higher in women with the CD36 AA genotype as compared to subjects with the GG genotype (Fig. 3(a)). Interestingly, serum IL-6 concentrations were lower in women with the AA and AG genotypes than they were in women with the GG genotype (Fig. 3(b)).

Association between TNF- $\alpha$ polymorphism and creatinine serum level and association between IL-6 polymorphism and IL-6 serum level

Fig. 4 shows that the women with the IL- 6 GG and TNF- $\alpha$ GG genotypes exhibited higher serum IL- 6 and creatinine concentrations, respectively, than did those with the $I L-6$ CC and TNF- $\alpha$ AA genotypes. Moreover, we did not observe a statistical association between the TNF- $\alpha$ SNP and serum TNF- $\alpha$ concentrations $(P>0 \cdot 05)$.

\section{Discussion}

Evidence suggests that there might be a sixth taste modality that is devoted to the oro-gustatory perception of dietary lipids ${ }^{(14,40)}$. Hence, it seems imperative to explore and better understand the mechanisms that underlie the oro-gustatory detection of dietary fat in order to help prevent and treat obesity $^{(5,41)}$. A number of studies have suggested that lingual CD36, a glycoprotein that is highly expressed in circumvallate papillae, is implicated in the perception of dietary fat taste ${ }^{(6,12-15)}$. In the present study, we confirm that obese women with the CD36 AA genotype (rs1761667) possess higher thresholds for lipid taste sensitivity than do those with GG genotypes.

Keller et $a l .{ }^{(20)}$ have provided preliminary evidence that CD36 is involved in human oral fat perception and the human attraction to added fats and oils in food. Pepino et al. ${ }^{(19)}$ have demonstrated that $C D 36$ gene polymorphism, which results in a decrease in the gene's expression, is responsible for an increase in the oral detection threshold of dietary lipids in obese subjects. Aside from the present study, no confirming or refuting report is available on this subject, particularly from developing countries where diets are rich in fat. The present data strongly suggested that the oro-sensorial perception of fat taste is altered in some obese subjects. Indeed, we showed that the A allele of $C D 36$ rs1761667 polymorphism in obese women, which was previously associated with decreased expression of the CD36 protein, is associated with a high oro-gustatory threshold detection for oleic acid. Conversely, the subjects with the $G$ allele were more sensitive in their oleic acid lingual detection as compared to the subjects with the A allele. These data corroborate not only the clinical findings of Pepino et $a l^{(19)}$ but also experimental data where an association between CD36 gene expression and oral fat detection has been demonstrated ${ }^{(42)}$. Mice with partial CD36 gene knockout $\left(\mathrm{CD} 6^{+} /^{-}\right)$had lower $\mathrm{CD} 36$ protein expression and a lower oral fat detection threshold than wild type animals $\left(\mathrm{CD} 36^{+} /{ }^{+}\right)$. The $\mathrm{CD} 36$ knockout $\left(\mathrm{CD} 36^{-} /^{-}\right)$failed to exhibit a spontaneous preference for fat.

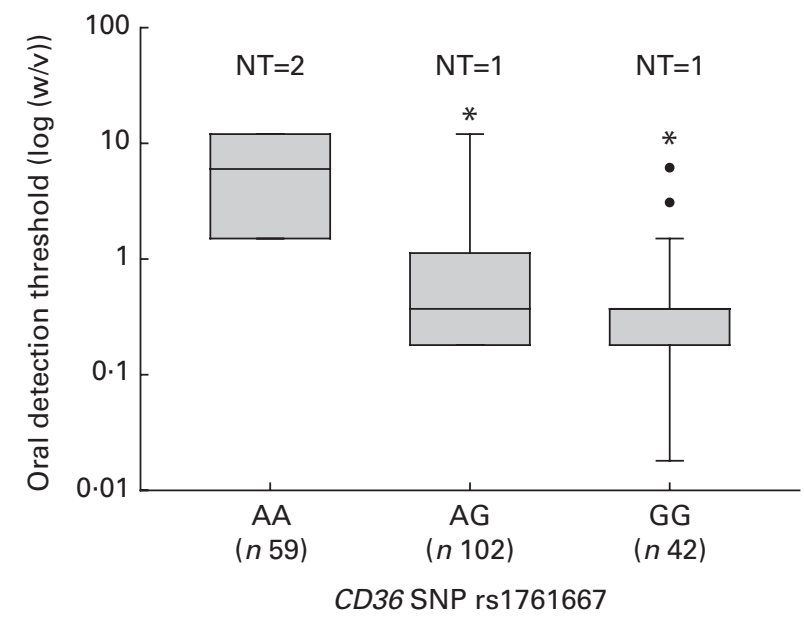

Fig. 1. Oleic acid detection thresholds in obese Tunisian women. The women ( $n$ 203) had either the AA genotype ( $n 59)$ or the GG $(n 42)$ or AG ( $n$ 102) genotype of the cluster of differentiation 36 (CD36) gene. The figure shows the box plots of the medians, first and third quartiles, standard deviations and extreme values. The difference between the three groups was statistically significant $\left(P<0.001\right.$; Kruskal-Wallis test). ${ }^{*}$ Median value was significantly different from that of the AA genotype $(P<0.05$; one-way ANOVA). The difference between the $A G$ and $G G$ genotypes was not statistically significant. NT, non-tasters. 

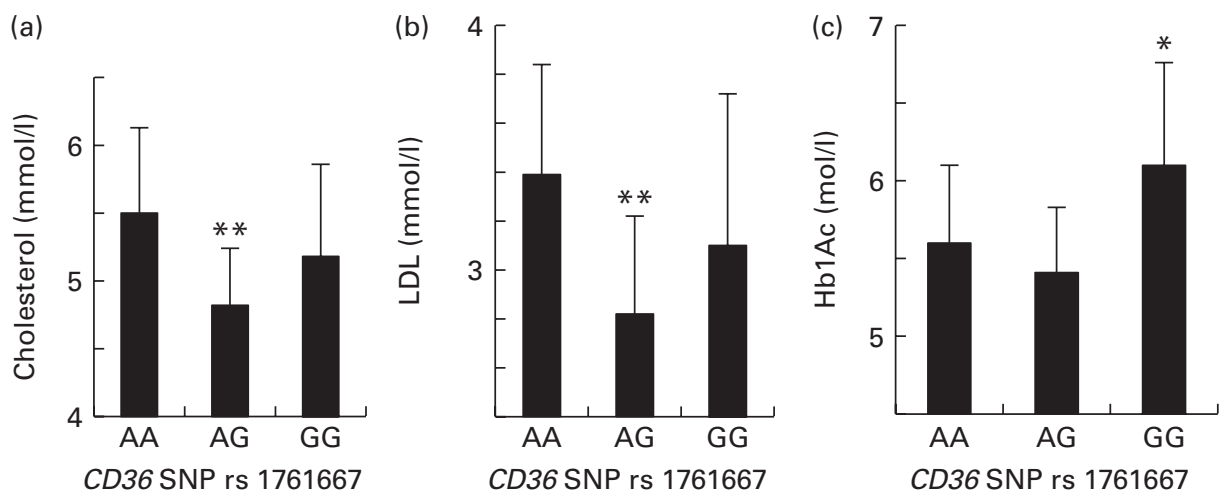

Fig. 2. Association between blood parameters and cluster of differentiation $36(C D 36)$ SNP in obese Tunisian women. Concentrations of cholesterol (a), LDL (b) and glycosylated $\mathrm{Hb}(\mathrm{HbA1c})$ (c) in women with the $\mathrm{AA}, \mathrm{AG}$ or $\mathrm{GG}$ genotype of the $C D 36$ gene. Values are means, with standard deviations represented by vertical bars. Mean value was significantly different from that of the AA genotype: ${ }^{\star} P<0.05,{ }^{\star \star} P<0.01$ (one-way ANOVA).

A low detection threshold for fat in the present study may not have been caused by the low expression of $\alpha$-gustducin, a marker of taste receptor cells. Indeed, alteration in CD36 expression is not related to changes in $\alpha$-gustducin expression $^{(42)}$. Moreover, $\alpha$-gustducin knockout mice, like wild type animals, exhibited an unaltered preference for dietary fat $^{(43)}$. It is possible that other proteins which are likewise involved in fat taste detection, such as GPR120, might also participate in low-fat taste sensitivity ${ }^{(44)}$. However, the CD36 and GPR120 receptors seem to be differently regulated in lipid taste perception ${ }^{(18,44)}$.

In the present study, we also observed that some of the subjects failed to detect oleic acid in the emulsions. These subjects were defined as non-tasters, and they were also reported by Kamphuis et al. ${ }^{(9)}$. The mutation responsible for gustatory insensitivity to fatty acid in non-taster subjects deserves further in-depth study.

We performed the present study on Tunisian obese women (who probably eat an above-average amount of fatty food due to cultural customs in Tunisia), because it has been shown that some obese subjects had a low sensitivity to oleic acid ${ }^{(35,45)}$. Oral and gastrointestinal sensitivity to oleic acid are related to each other, and they are decreased in obese subjects ${ }^{(35)}$ Nonetheless, the present association studies cannot distinguish whether the decreased sensitivity to fat in obese women is a cause or a consequence of obesity. However, Stewart et al. ${ }^{(11)}$ have shown that oral sensitivity towards oleic acid in lean subjects is decreased with a high-fat diet and increased with a low-fat diet. Brennan et al. ${ }^{(46)}$ have reported that acute dietary restriction in obese subjects enhances their gastrointestinal sensitivity to fat, and this is associated with an increased effect of fat on satiation. In addition, a high-fat diet has been shown to decrease the expression of CD36 in mice ${ }^{(42)}$.

We observed an association between the CD36 AA genotype and high serum levels of cholesterol and LDL in obese women. Because the CD36 A allele was previously associated with reduced expression of the CD36 gene, it is possible that high blood lipid concentrations are the result of their curtailed uptake by adipocytes that also express CD36; in this case, it acts as a fatty acid transporter ${ }^{(47,48)}$. Moreover, CD36 gene polymorphisms have been significantly associated with high TAG concentrations among ethnic Chinese in Taiwan ${ }^{(49)}$.

Interestingly, obese women with the CD36 G allele had higher plasma HbA1c concentrations than women with the A allele. These observations corroborate the findings of Rać et al. ${ }^{(50)}$, who have shown that the GG genotype was significantly associated with higher HbA1c concentrations as compared to the AA genotype of CD36 in obese children.

We observed that obese women had high IL- 6 and TNF- $\alpha$ serum concentrations. Homozygous women with the CD36 AA genotype had higher TNF- $\alpha$ serum concentrations than did those with the GG or AG genotypes. Conversely, IL-6 serum concentrations were higher in women with the GG genotype than they were in women with the AA or AG genotypes. The importance of the association of high serum levels of TNF- $\alpha$ with the CD36 AA genotype and the association of high serum levels of IL- 6 with the CD36 GG genotype is not well understood. These cytokines play a key role in the regulation of insulin sensitivity in subjects who are suffering
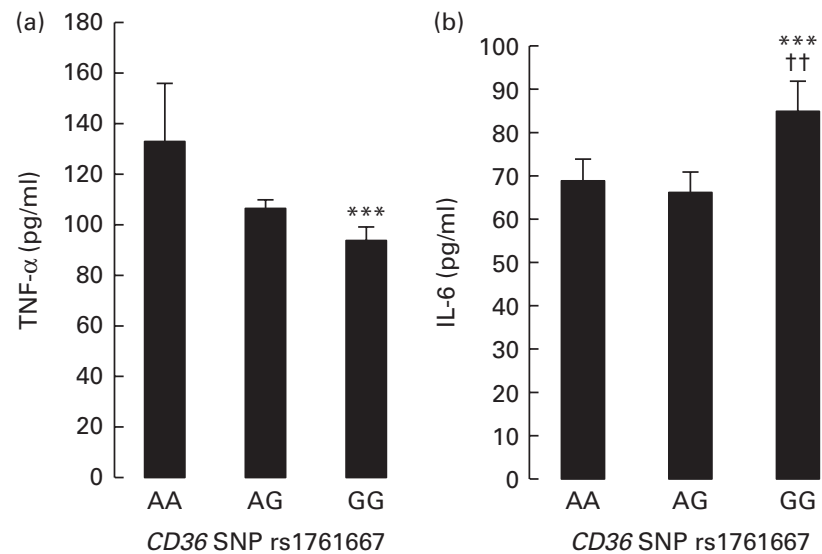

Fig. 3. Serum TNF- $\alpha$ (a) and IL-6 (b) concentrations in obese Tunisian women with the AA, AG or GG genotype of the cluster of differentiation 36 (CD36) gene. The serum concentrations of cytokines were determined as described in the Materials and Methods section of the present paper. Values are means, with standard deviations represented by vertical bars. ${ }^{\star \star *}$ Mean value was significantly different from that of the AA genotype $(P<0.001$; one-way ANOVA). ††Mean value was significantly different from that of the AG genotype $(P<0.01$; Fisher's exact test). 


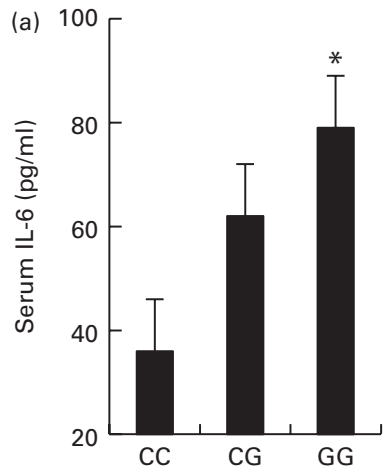

IL-6 SNP rs 1800795 (b)

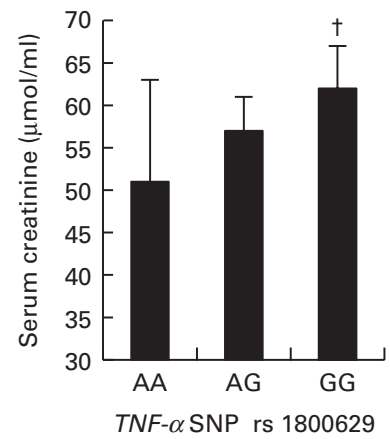

Fig. 4. Serum IL-6 (a) concentrations in obese Tunisian women with the IL-6 polymorphisms CC, CG or GG. Serum creatinine (b) concentrations in obese Tunisian women with the TNF- $\alpha$ polymorphisms AA, AG or GG. Values are means, with standard deviations represented by vertical bars. * Mean value was significantly different from that of the CC genotype $(P<0.05$; Fisher's exact test). †Mean value was significantly different from that of the $A A$ genotype $(P<0.05$; one-way ANOVA).

from obesity and metabolic syndrome ${ }^{(51)}$. The SNP of these cytokines have been suggested to predispose for obesity ${ }^{(52)}$. The homozygous subjects with the GG genotype exhibited high serum IL-6 concentrations. These observations are in close agreement with the results of Pereira et al. ${ }^{(53)}$, who studied the association between the $I L-6$ gene and plasma IL- 6 concentrations in community-dwelling and institutionalised older women. Those authors reported that women with the IL-6 GG genotype had high IL-6 serum concentrations. High serum IL-6 concentration in homozygous subjects with the GG genotype might take part in increased fat oxidation in response to fat load in obesity, as has been suggested elsewhere ${ }^{(54)}$. With regards to TNF- $\alpha$, we noticed a positive relationship between circulating creatinine concentrations and the $T N F-\alpha$ GG genotype, which indicates that the present subjects might be at risk for renal complications. Chang et $a l .{ }^{(55)}$ have shown that the $G$ allele of the $T N F-\alpha$ gene was associated with high serum creatinine concentrations that increased the risk for contrast-induced nephropathy. We also observed a significant association between $I L-6$ and $T N F-\alpha$ gene polymorphisms in obese women, which indicates that inflammatory status, as indicated by pro-inflammatory cytokines, is a key element of obesity in these women. Curtis \& Singh ${ }^{(56)}$ have likewise shown that the SNP of these two cytokines predispose for obesity.

Finally, we can state that a major value of the present study is that it validates the importance of a common CD36 SNP rs1761667 in obese women. The present results must be confirmed by additional studies in other developing countries. It is also possible that in the present study, there might be an influence of female sex hormones on fat taste perception and other parameters. At this stage, it is difficult to determine whether oral fat perception sensitivity affects fat intake or body weight. Future studies are needed to answer these important questions. The stimulation of taste receptors, such as $\mathrm{CD} 36$, by synthetic fatty acid analogues within the oral cavity may provide a new target for obesity treatment.

\section{Acknowledgements}

The present study was partly supported by funds from the Ministry of Higher Education and Research, France (to N. A. K.), and by the Specific Research Project of Masaryk University Brno (to O. S.). The present research received no grants from the commercial or not-for-profit sectors. The funders had no role in the design, analysis or writing of the present article.

The authors' contributions are as follows: N. A. K. designed the research (project conception, development of the overall research plan and study oversight); I. M. conducted the research (hands-on conduct of the experiment and data collection); N. A. K. and O. S. wrote the manuscript; O. S. supervised the SNP research and statistical analysis; J. P. completed the technical part of the SNP analysis and participated in writing the manuscript; A. A., M. F., A. B. and M. Z. provided the facilities in the sample collections; N. A. K. and Z. T. supervised the study. All authors have read and approved the final content of the manuscript.

The authors declare no conflicts of interest.

\section{References}

1. Lafortuna CL, Adorni F, Agosti F, et al. (2009) Factor analysis of metabolic syndrome components in severely obese girls and boys. J Endocrinol Invest 32, 552-558.

2. De Pergol G \& Silvestris F (2013) Obesity as a major risk factor for cancer. $J$ Obes 2013, 291546.

3. Herring MP, Sailors MH \& Bray MS (2013) Genetic factors in exercise adoption, adherence and obesity. Obes Rev 15, $29-39$.

4. Mattes RD (2007) Effects of linoleic acid on sweet, sour, salty, and bitter taste thresholds and intensity ratings of adults. Am J Physiol Gastrointest Liver Physiol 292, G1243-G1248.

5. Dramane G, Akpona S, Simonin AM, et al. (2011) Cell signaling mechanisms of gustatory perception of lipids: can the taste cells be the target of anti-obesity agents? Curr Med Chem 18, 3417-3422.

6. Laugerette F, Passilly-Degrace P, Patris B, et al. (2005) CD36 involvement in orosensory detection of dietary lipids, spontaneous fat preference, and digestive secretions. J Clin Invest 115, 3177-3184.

7. Chalé-Rush A, Burgess JR \& Mattes RD (2007) Evidence for human orosensory (taste?) sensitivity to free fatty acids. Chem Senses 32, 423-431.

8. Nasser JA, Kissileff HR, Boozer CN, et al. (2001) PROP taster status and oral fatty acid perception. Eat Behav 2, 237-245.

9. Kamphuis MM, Saris WH \& Westerterp-Plantenga MS (2003) The effect of addition of linoleic acid on food intake regulation in linoleic acid tasters and linoleic acid non-tasters. Br J Nutr 90, 199-206.

10. Stewart JE, Feinle-Bisset C \& Keast RS (2011) Fatty acid detection during food consumption and digestion: associations with ingestive behavior and obesity. Prog Lipid Res 50, 225-233.

11. Stewart JE \& Keast RS (2012) Recent fat intake modulates fat taste sensitivity in lean and overweight subjects. Int $J$ Obes (Lond) 36, 834-842.

12. Cartoni C, Yasumatsu K, Ohkuri T, et al. (2010) Taste preference for fatty acids is mediated by GPR40 and GPR120. J Neurosci 30, 8376-8382.

13. Abumrad NA (2005) CD36 may determine our desire for dietary fats. J Clin Invest 115, 2965-2967. 
14. Gilbertson TA \& Khan NA (2013) Cell signaling mechanisms of oro-gustatory detection of dietary fat: advances and challenges. Prog Lipid Res 53C 82-92.

15. Abdoul-Azize S, Selvakumar S, Sadou H, et al. (2014) $\mathrm{Ca}^{2+}$ signaling in taste bud cells and spontaneous preference for fat: unresolved roles of CD36 and GPR120. Biochimie 96, $8-13$.

16. Galindo MM, Voigt N, Stein J, et al. (2012) G protein-coupled receptors in human fat taste perception. Chem Senses 37, $123-139$

17. Sclafani A, Ackroff K \& Abumrad NA (2007) CD36 gene deletion reduces fat preference and intake but not postoral fat conditioning in mice. Am J Physiol Regul Integr Comp Physiol 293, R1823-R1832.

18. Sclafani A, Zukerman S \& Ackroff K (2013) GPR40 and GPR120 fatty acid sensors are critical for postoral but not oral mediation of fat preferences in the mouse. Am J Physiol Regul Integr Comp Physiol 305, R1490-R1497.

19. Pepino MY, Love-Gregory L, Klein L, et al. (2012) The fatty acid translocase gene, CD36, and lingual lipase influence oral sensitivity to fat in obese subjects. J Lipid Res $\mathbf{5 3}$, $561-566$.

20. Keller KL, Liang LC, Sakimura J, et al. (2012) Common variants in the $C D 36$ gene are associated with oral fat perception, fat preferences, and obesity in African Americans Obesity (Silver Spring) 20, 1066-1073.

21. Dandona P, Ghanim H \& Chaudhuri A (2011) An inflammatory tale from 3 fatty depots. J Am Coll Cardiol 58, 256-257.

22. Fried SK, Bunkin DA \& Greenberg AS (1998) Omental and subcutaneous adipose tissues of obese subjects release interleukin-6: depot difference and regulation by glucocorticoid. $J$ Clin Endocrinol Metab 83, 847-850.

23. Steensberg A, Fischer CP, Keller C, et al. (2003) IL-6 enhances plasma IL-1ra, IL-10, and cortisol in humans. $A m \mathrm{~J}$ Physiol Endocrinol Metab 285, E433-E437.

24. Poitou C, Lacorte JM, Coupaye M, et al. (2005) Relationship between single nucleotide polymorphisms in leptin, IL-6 and adiponectin genes and their circulating product in morbidly obese subjects before and after gastric banding surgery. Obes Surg 15, 11-23.

25. Bouhaha R, Baroudi T, Ennafaa H, et al. (2010) Study of TNF $\alpha-308 \mathrm{G} / \mathrm{A}$ and IL6 $174 \mathrm{G} / \mathrm{C}$ polymorphisms in type 2 diabetes and obesity risk in the Tunisian population. Clin Biochem 6, 549-552.

26. Qi C \& Pekala PH (2000) Tumor necrosis factor- $\alpha$-induced insulin resistance in adipocytes. Proc Soc Exp Biol Med 223, $128-135$

27. Wilson AG, Symons JA, McDowell TL, et al. (1997) Effects of a polymorphism in the human tumor necrosis factor $\alpha$ promoter on transcriptional activation. Proc Natl Acad Sci U S A 94, 3195-3199.

28. Um JY \& Kim HM (2003) Frequencies of the tumor necrosis factor gene polymorphisms in the Korean population. Hereditas 139, 184-188.

29. Kubaszek A, Pihlajamäki J, Komarovski V, et al. (2003) Promoter polymorphisms of the TNF- $\alpha$ (G-308A) and IL- 6 (C-174G) genes predict the conversion from impaired glucose tolerance to type 2 diabetes: the Finnish Diabetes Prevention Study. Diabetes 52, 1872-1976.

30. Popkin BM, Adair LS \& Ng SW (2012) Global nutrition transition and the pandemic of obesity in developing countries. Nutr Rev 70, 3-21.

31. El Ati J, Traissac P, Delpeuch F, et al. (2012) Gender obesity inequities are huge but differ greatly according to environment and socio-economics in a North African setting: a national cross-sectional study in Tunisia. PLOS ONE 7 , e48153.

32. Friedewald WT, Levy RI \& Fredrickson DS (1972) Estimation of the concentration of low-density lipoprotein cholesterol in plasma without use of preparative ultracentrifuge. Clin Chem 18, 499-502.

33. Kaplan LA, Cline D, Gartside $P$, et al. (1982) Hemoglobin $A_{1}$ in hemolysates from healthy and insulin-dependent diabetic children, as determined with a temperature-controlled minicolumn assay. Clin Chem 28, 13-18

34. Chalé-Rush A, Burgess JR \& Mattes RD (2007) Multiple routes of chemosensitivity to free fatty acids in humans. Am J Physiol Gastrointest Liver Physiol 292, G1206-G1212.

35. Stewart JE, Seimon RV, Otto B, et al. (2011) Marked differences in gustatory and gastrointestinal sensitivity to oleic acid between lean and obese men. Am J Clin Nutr 93, 703-711.

36. Drtilkova I, Sery O, Theiner P, et al. (2008) Clinical and molecular-genetic markers of ADHD in children. Neuro Endocrinol Lett 29, 320-327.

37. Sery O, Hladilova R, Novotny M, et al. (2003) Association between $-174 \mathrm{G} / \mathrm{C}$ polymorphism of interleukin-6 gene and alcoholism. Acta Neuropsychiatr 15, 257-261.

38. Fernandez-Real JM, Vayreda M, Richart C, et al. (2001) Circulating interleukin 6 levels, blood pressure, and insulin sensitivity in apparently healthy men and women. $J$ Clin Endocrinol Metab 86, 1154-1159.

39. Aukrust P, Müller F, Lien E, et al. (1999) Tumor necrosis factor (TNF) system levels in human immunodeficiency virus-infected patients during highly active antiretroviral therapy: persistent TNF activation is associated with virologic and immunologic treatment failure. J Infect Dis 179, 74-82.

40. Running CA, Mattes RD \& Tucker RM (2013) Fat taste in humans: sources of within- and between-subject variability. Prog Lipid Res 52, 438-445.

41. Mattes RD \& Considine RV (2013) Oral processing effort, appetite and acute energy intake in lean and obese adults. Physiol Behav 120, 173-181.

42. Martin C, Passilly-Degrace P, Gaillard D, et al. (2011) The lipid-sensor candidates CD36 and GPR120 are differentially regulated by dietary lipids in mouse taste buds: impact on spontaneous fat preference. PLOS ONE 6, e24014.

43. Sclafani A, Zukerman S, Glendinning JI, et al. (2007) Fat and carbohydrate preferences in mice: the contribution of $\alpha$-gustducin and Trpm5 taste-signaling proteins. Am J Physiol Regul Integr Comp Physiol 293, R1504-R1513.

44. Ozdener MH, Subramaniam S, Sundaresan S, et al. (2014) CD36- and GPR120-mediated $\mathrm{Ca}^{2+}$ signaling in human taste bud cells mediates differential responses to fatty acids and is altered in obese mice. Gastroenterology 146, 995-1005.

45. Stewart JE, Feinle-Bisset C, Golding M, et al. (2010) Oral sensitivity to fatty acids, food consumption and BMI in human subjects. Br J Nutr 104, 145-152.

46. Brennan IM, Seimon RV, Luscombe-Marsh ND, et al. (2011) Effects of acute dietary restriction on gut motor, hormone and energy intake responses to duodenal fat in obese men. Int J Obes (Lond) 35, 448-456.

47. Nakamura MT, Yudell BE \& Loor JJ (2013) Regulation of energy metabolism by long-chain fatty acids. Prog Lipid Res 53C, 124-144.

48. Zhou D, Samovski D, Okunade AL, et al. (2012) CD36 level and trafficking are determinants of lipolysis in adipocytes. FASEB J 26, 4733-4742.

49. Chien KL, Hsu HC, Liu PH, et al. (2012) Common sequence variants in CD36 gene and the levels of triglyceride and 
high-density lipoprotein cholesterol among ethnic Chinese in Taiwan. Lipids Health Dis 11, 174.

50. Rać ME, Krupa B, Garanty-Bogacka B, et al. (2012) Polymorphism of CD36 gene, carbohydrate metabolism and plasma CD36 concentration in obese children. A preliminary study. Postepy Hig Med Dosw (Online) 66, 954-958.

51. Bougnères $P$ (2002) Genetics of obesity and type 2 diabetes: tracking pathogenic traits during the predisease period. Diabetes 51, S295-S303.

52. Curti MLR, Jacob P, Borges MC, et al. (2011) Studies of gene variants related to inflammation, oxidative stress, dyslipidemia, and obesity: implications for a nutrigenetic approach. $J$ Obes 2011, 497401.
53. Pereira DS, Garcia DM, Narciso M, et al. (2011) Effects of $174 \mathrm{G} / \mathrm{C}$ polymorphism in the promoter region of the interleukin-6 gene on plasma IL-6 levels and muscle strength in elderly women. Braz J Med Biol Res 44, 123-129.

54. Hoene M \& Weigert C (2008) The role of interleukin-6 in insulin resistance, body fat distribution and energy balance. Obes Rev 9, 20-29.

55. Chang CF, Lu TM, Yang WC, et al. (2013) Gene polymorphisms of interleukin-10 and tumor necrosis factor- $\alpha$ are associated with contrast-induced nephropathy. Am J Nephrol 37, 110-117.

56. Curtis JR \& Singh JA (2011) Use of biologics in rheumatoid arthritis: current and emerging paradigms of care. Clin Ther 33, 679-707. 